\title{
Exploring Neuroprotective Drug Therapies for Intracerebral Hemorrhage
}

\author{
Hiroshi Katsuki ${ }^{1, *}$ \\ ${ }^{1}$ Department of Chemico-Pharmacological Sciences, Graduate School of Pharmaceutical Sciences, Kumamoto University, \\ 5-1 Oe-honmachi, Kumamoto 862-0973, Japan
}

Received August 20, 2010; Accepted October 4, 2010

\begin{abstract}
Intracerebral hemorrhage (ICH) is a devastating neurological disorder with high mortality and poor prognosis, for which virtually no effective drug therapies are available at present. Experimental animal models, based on intrastriatal injection of collagenase or autologous blood, have enabled great advances in elucidation of cellular/molecular events contributing to brain pathogenesis associated with ICH. Many lines of evidence indicate that blood constituents, including hemoglobin-derived products as well as proteases such as thrombin, play important roles in the pathogenic events. Inflammatory reactions involving neutrophils, activated microglia, and production of proinflammatory cytokines also constitute a critical aspect of pathology leading to neurodegeneration and tissue damage. Efforts are continuing to find drugs that potentially alleviate pathological and neurological outcomes of ICH. Various drugs that possess antioxidative, antiinflammatory or neurotrophic/neuroprotective properties have been demonstrated to produce therapeutic effects on ICH animal models. Drugs already in clinical use such as minocycline, statins, and several nuclear receptor ligands are among the list of effective drugs, but whether they also show therapeutic efficacy in human ICH patients remains unproven. Here, current knowledge of $\mathrm{ICH}$ pathogenesis and problems arising with respect to exploration of new drug candidates are discussed.
\end{abstract}

Keywords: hemorrhagic stroke, matrix metalloproteinase, heme, peroxisome proliferator-activated receptor, retinoid

\section{Contents}

1. Introduction

2. Molecules involved in ICH pathogenesis

2.1. Thrombin

2.2. Matrix metalloproteinases

2.3. Heme and iron

2.4. Glutamate

2.5. Complement
2.6. Proinflammatory cytokines and other inflammatory mediators

2.7. Protective factors

3. Potential pharmacological interventions

3.1. Free radical scavengers

3.2. Growth factors and cytokines

3.3. Minocycline

3.4. Statins

3.5. Nuclear receptor ligands

3.6. Others

4. Perspectives

\section{Introduction}

Intracerebral hemorrhage (ICH) is a type of acute stroke characterized by extravasation of blood into brain

*Corresponding author. hkatsuki@gpo.kumamoto-u.ac.jp Published online in J-STAGE on November 11, 2010 (in advance) doi: 10.1254/jphs.10R05CR

Invited article parenchyma and formation of hematoma, leading to edema and tissue damage in the brain. ICH represents approximately $15 \%$ of all strokes: hemorrhage resulting from denaturalization of vascular walls such as microaneurysm rupture occurs preferentially in several brain regions including the striatum (caudate-putamen) and the thalamus (1). No satisfactory treatments have been developed against this disorder, and patients suffer from high mortality and poor prognosis accompanied by en- 
during brain dysfunction. In addition, ischemic stroke is frequently associated with secondary hemorrhagic transformation that aggravates brain injury and neurological symptoms (2). Overall, hemorrhagic events within the brain tissue are serious medical problems. Current strategies for clinical management of ICH are recently reviewed elsewhere (3).

Experimental animal models of $\mathrm{ICH}$, based on injection of either collagenase (that disrupts basal lamina of blood vessels) or autologous blood into brain parenchyma (usually into the striatum), have been developed (4), which greatly contributed to advances in the understanding of complicated pathogenic mechanisms of ICH. These experimental models have also been used to explore candidates for drug therapies for ICH. Here, an overview about the cellular and molecular mechanisms involved in pathogenic events after ICH is given in this review. Potential therapeutic strategies proven to be effective in animal models are also outlined, with special emphasis on strategies achieved by drug treatments.

\section{Molecules involved in ICH pathogenesis}

Formation of hematoma within the brain parenchyma after ICH inevitably brings physical damage to brain tissue. The 'mass effect' is an important factor in the pathogenic events in ICH (1), although it may be difficult to manage this effect directly by drug therapies. Perhaps equally important factors that contribute to ICH pathogenesis are several blood constituents such as thrombin and hemoglobin as well as its degradation products, which exert biological actions or toxic influences on brain cells. These events, primarily resulting from blood extravasation, also trigger secondary reactions in the brain parenchyma including recruitment of additional proteases, inflammatory responses, and intrinsic cytoprotective systems.

\subsection{Thrombin}

Thrombin is a serine protease that plays a pivotal role in the blood coagulation cascade. Besides its physiological role, substantial lines of evidence indicate that thrombin participates in various pathological conditions in the brain (5). In the case of ICH, a large amount of blood-derived thrombin invades the brain tissue and exerts biological actions through its proteolytic activity (Fig. 1A). The substrates for thrombin include proteinaseactivated receptors that transduce intracellular signals via trimeric $\mathrm{G}$ proteins (6).

The role of thrombin in ICH pathogenesis was first suggested by its possible involvement in edema formation. That is, injection of whole blood into the striatum of rats induced edema, which was prevented by addition of hirudin, a thrombin inhibitor (7). Edema induced by autologous blood injection into the striatum was attenuated also by argatroban, another inhibitor of thrombin, even when the drug was systemically administered from $6 \mathrm{~h}$ after blood injection (8). ICH-associated edema results from disruption of the blood-brain barrier and death of brain parenchymal cells, both of which may be induced by thrombin (9).

To elucidate the mechanisms of thrombin-induced cell death and tissue injury in the brain parenchyma, we set out for the experiments using an organotypic slice culture preparation (10). Application of thrombin to rat corticostriatal cultures induced delayed neuron death in the cortical region and shrinkage of the striatal region. Various pharmacological examinations revealed distinct properties of the mechanisms of injury between the cerebral cortex and the striatum. For example, extracellular signal-regulated kinase (ERK), p38, and c-Jun $N$-terminal kinase (JNK), three major members of mitogen-activated protein kinase (MAPK) family, all contributed to thrombin-induced injury of the striatum, whereas ERK, but not p38 or JNK, was involved in cortical injury. In addition, depletion of microglia from slice cultures rescued striatal tissue, but not cortical cells, from thrombininduced injury, suggesting that microglia participate only in striatal tissue injury (10). Involvement of MAPKs and activated microglia in striatal tissue injury was confirmed by an in vivo study where thrombin was directly injected into the striatum of adult rats (11). On the other hand, plasminogen was found to cooperate with thrombin in inducing cortical injury but not striatal injury (12).

Thrombin-mediated cellular injury may also be mediated by activation of matrix metalloproteinase (MMP)- 9 (see below). That is, concurrent application of MMP-9 exacerbates cytotoxicity of thrombin in neurons in primary culture, and thrombin cytotoxicity is partially attenuated by MMP inhibitors. Moreover, brain damage induced by autologous blood injection is synergistically attenuated by deletion of the gene encoding MMP-9 and administration of the thrombin inhibitor hirudin (13).

\subsection{Matrix metalloproteinases}

MMPs are a large group of proteases that act as cell surface sheddases, thereby regulating intercellular signaling (14). After hemorrhagic events in the brain, several members of the MMP family are recruited and involved in pathogenic processes. An early study on collagenase injection model (15) reported that the MMP inhibitor BB-1101 could reduce brain edema when administered 6 $\mathrm{h}$ after induction of ICH. In human ICH patients, expression of MMP-9 and MMP-3 increases after the incident (16). MMP-9 expression is induced in astrocytes and neurons in the perihematomal area, possibly by an action 


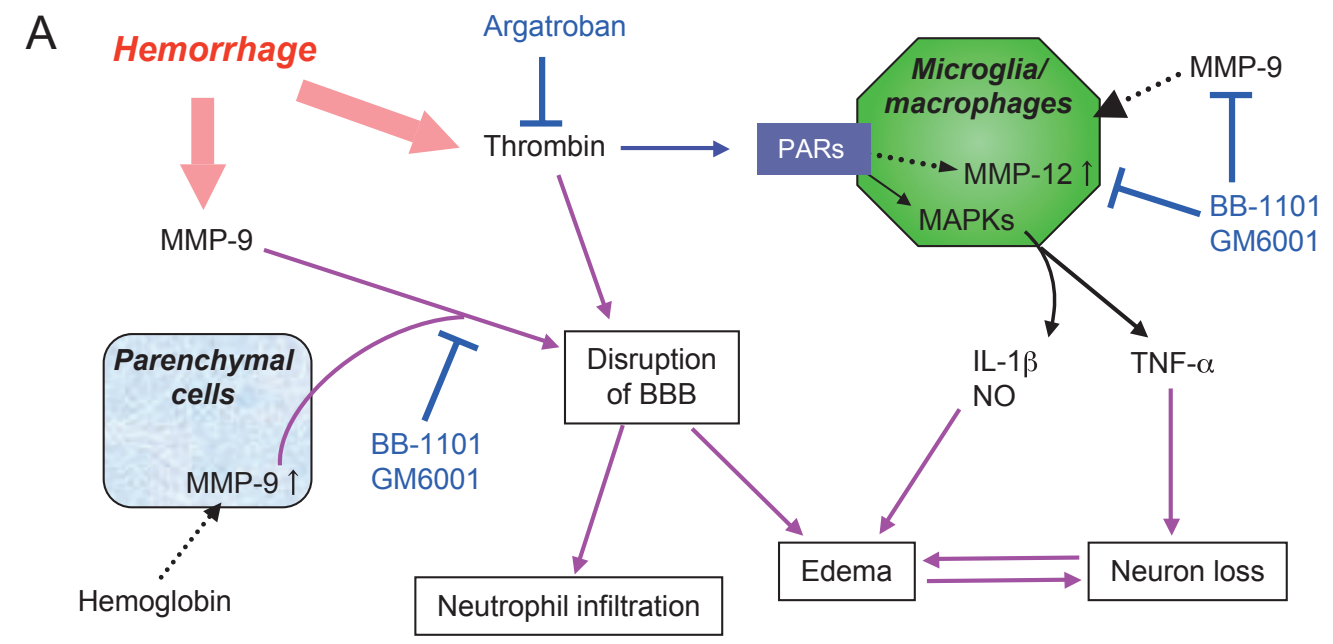

$\mathrm{B}$

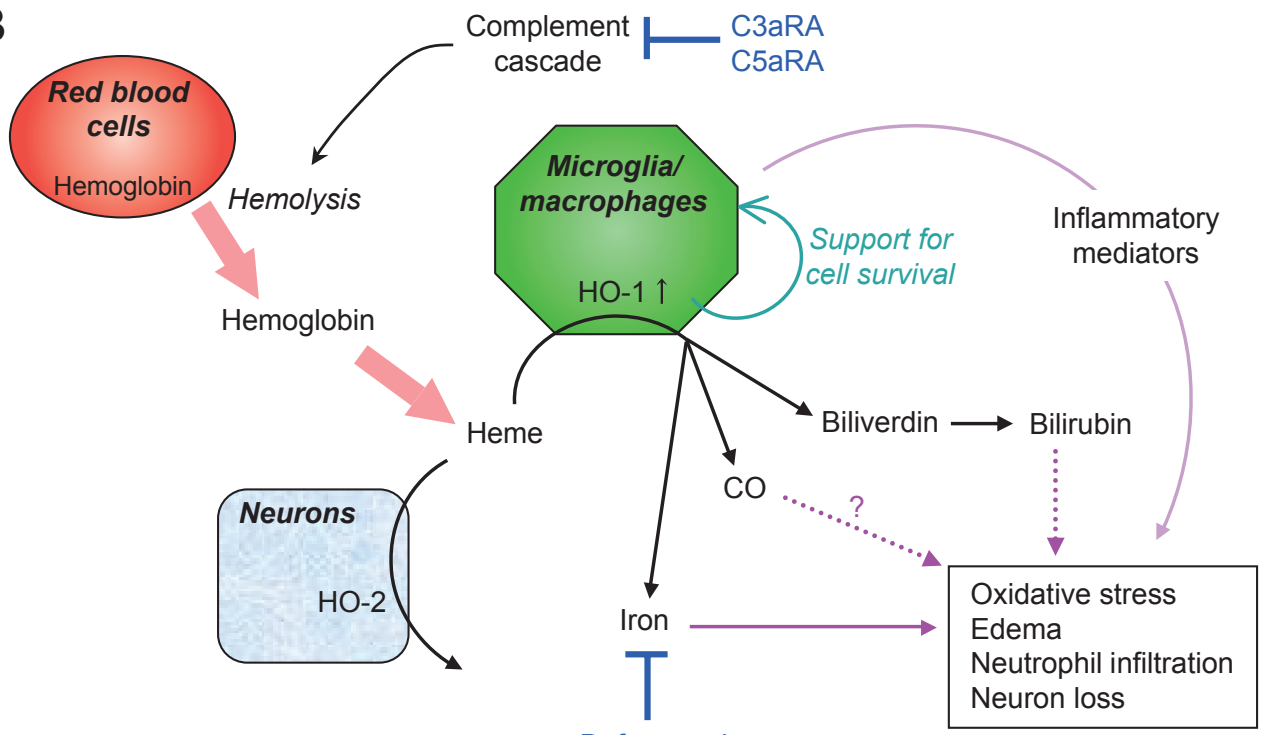

Deferoxamine

Clioquinol

Fig. 1. Putative mechanisms of ICH pathogenesis. A) Mechanisms with emphasis on the roles of proteases. Hemorrhage results in invasion of blood constituents such as prothrombin into the brain. Prothrombin is converted to its active form thrombin, and the protease disrupts the blood-brain barrier (BBB), thereby promoting formation of edema and infiltration of neutrophils. In addition, thrombin stimulates proteinase-activated receptors (PARs) on microglia/macrophages, activates these cells via recruitment of mitogen-activated protein kinases (MAPKs), and enhances production of several inflammatory mediators including TNF- $\alpha$, IL$1 \beta$, and nitric oxide (NO). These mediators contribute to neuron damage and edema formation. On the other hand, MMP-9 derived from both blood and brain parenchymal cells (neurons, astrocytes, and vascular endothelial cells) also contribute to edema formation, presumably via disruption of BBB and via actions (either directly or indirectly) onto microglia/macrophages. Expression of MMP-9 within the brain can be upregulated by hemoglobin. Aside from MMP-9, involvement of other members of MMPs such as MMP-3 (not shown here) and MMP-12 has been suggested in several studies. Expression of MMP-12 in microglia/macrophages is stimulated by thrombin. Argatoroban inhibits thrombin, whereas BB-1101 and GM6001 inhibit MMPs, thereby lessening pathological events associated with ICH such as edema formation. B) Mechanisms with relation to hemolysis. Recruitment of complement cascade results in lysis of red blood cells. Hemolysis causes release of hemoglobin and heme, both of which are taken up by brain cells such as microglia and neurons. ICH is also associated with robust induction of HO-1 in microglia/macrophages, and the enzyme catalyzes degradation of heme into biliverdin (which is converted to bilirubin), carbon monoxide (CO), and iron. Iron (and presumably other products also) contributes to pathological changes such as increase in oxidative stress, formation of edema, infiltration of neutrophils, and induction of neuron death. Moreover, HO-1 may support survival of microglia/macrophages and consequently, may sustain deleterious inflammatory reactions brought about by these cells. Neurons express HO-2, the constitutive HO isoform, which might be able to participate in heme catabolism. C3a- and C5a-receptor antagonists (C3aRA and C5aRA) interrupt the complement cascade, whereas deferoxamine and clioquinol chelate free ion, all of which have been reported to alleviate pathological events in ICH animal models. 
of hemoglobin (17). Increased MMP-9 is associated with the extent of perihematomal edema, whereas increased MMP-3 is associated with high mortality (16). Experiments using MMP-9-deficient mice (17) demonstrated that MMP-9 derived from both blood and brain parenchyma contributes to edema formation after autologous blood injection (Fig. 1A). In addition, MMP-9-deficient mice displayed lower levels of neurodegeneration, neutrophil infiltration, and microglia/macrophage reactions than wild-type mice (13). In the collagenase injection model, MMP-9 expression was found mainly in neurons and vascular endothelial cells, and administration of the MMP inhibitor GM6001, beginning $2 \mathrm{~h}$ after induction of $\mathrm{ICH}$, attenuated neutrophil infiltration, oxidative stress, brain edema, neurodegeneration, and neurological impairment (18). With regard to MMP-3, early induction of this enzyme may contribute to brain damage in combination with other proteases such as MMP-9 and thrombin (19). Other lines of evidence indicate that MMP-12 may play a key role in the pathogenesis of ICH. That is, MMP-12 was induced most prominently among MMP isozymes in the collagenase-injection model in rats and mice (20, 21), and MMP-12-deficient mice showed better functional recovery after ICH as well as reduced levels of recruitment of microglia/macrophages in the perihematomal region (21).

It should be noted that several studies reported conflicting results. For example, a study on MMP-9-deficient mice showed that collagenase injection into the striatum of the mutant mice resulted in enhanced bleeding, increased mortality, and exacerbated neurological deficits. These changes may be attributable to heightened expression of MMP-2 and MMP-3 in response to ICH, together with lowered levels of collagen in the brain of MMP-9deficient mice (22). In addition, systemic administration of BB-94, a broad spectrum MMP inhibitor, from $30 \mathrm{~min}$ before collagenase injection increased hemorrhagic volume and the number of cells exhibiting DNA fragmentation (23).

\subsection{Heme and iron}

Aside from proteases, important blood constituents contributing to $\mathrm{ICH}$ pathogenesis are hemoglobin and its degradation products. Following ICH, a large number of red blood cells penetrate into brain parenchyma. Hemolysis does not occur promptly after ICH, but rather, proceeds slowly, taking several days to weeks (24). Hemoglobin is released from lysed red blood cells, heme is liberated from hemoglobin, and hemoglobin as well as heme is taken up by brain parenchymal cells such as microglia and neurons $(24,25)$.

Heme is degraded by heme oxygenases (HOs) into biliverdin, iron, and carbon monoxide, and heme itself or its degradation products may contribute to formation of brain edema (26). The major isoforms of HOs are HO-1 and HO-2, the former of which is an inducible isoform. After induction of ICH by collagenase or injection of autologous blood, robust expression of HO-1 is induced predominantly in non-neural cells such as microglia/ macrophages and endothelial cells $(27,28)$. Earlier studies on ICH models in pigs and rabbits demonstrated that tin-mesoporphyrin, an isoform-nonselective HO inhibitor, attenuated edema formation and neuron loss $(27,29)$. A later study on HO-1-deficient mice also suggested a deleterious role of HO-1 activity in ICH pathogenesis. That is, ablation of the HO-1 gene reduced injury volume, neutrophil infiltration, microglia/macrophage activation, and oxidative damage associated with ICH (28).

We recently proposed a novel role of $\mathrm{HO}-1$ in $\mathrm{ICH}$ pathogenesis. As was the case with thrombin cytotoxicity in vivo (11), neuroprotective effects of MAPK inhibitors suggested involvement of MAPKs in the pathogenesis of rat ICH model based on collagenase injection (30). Interestingly, we also found that administration of MAPK inhibitors triggered apoptotic cell death of microglia in the perihematomal region. Consistent with the occurrence of microglial cell death, the number of activated microglia was decreased by MAPK inhibition. Similar results were obtained in organotypic slice cultures treated with thrombin, where MAPK inhibition resulted in induction of apoptotic cell death in striatal microglia (31). Further examinations revealed that HO-1 expression was induced in activated microglia in a p38-dependent manner and was involved in maintenance of survival of these cells during thrombin insults (32). Therefore, one of the roles of HO-1 in ICH pathogenesis may be that the enzyme supports the survival of activated microglia, thereby sustaining and expanding deleterious influences of these cells onto other brain cells such as neurons and oligodendrocytes.

Iron derived from heme degradation may also play a key role in ICH pathogenesis, presumably via acceleration of oxidative stress. After autologous blood injection in rats, induction of HO-1 is followed by a gradual increase in tissue levels of non-heme iron (33). A recent clinical study showed that high serum levels of ferritin, a soluble protein for iron storage, are associated with poor outcome in ICH patients, suggesting that iron is involved in brain damage by ICH (34). Consistent with this idea, several studies on animal models of ICH showed that the iron chelator deferoxamine attenuated tissue damage and neurological deficits. For instance, intraperitoneal administration of deferoxamine starting from 2 or $6 \mathrm{~h}$ after autologous blood injection lessened brain edema, oxidative stress, and motor function deficits in rats (35). Another study on aged rats showed that deferoxamine was 
effective in reducing brain edema and motor dysfunction even when administration of the drug was delayed 12 and $48 \mathrm{~h}$, respectively, after autologous blood injection (36). However, the therapeutic efficacy of deferoxamine might depend on the type of ICH model. Reports mentioned above demonstrating beneficial effects of deferoxamine are based on the model made by autologous blood injection, whereas deferoxamine did not improve the outcome of the collagenase-induced ICH model in rats (37). On the other hand, a study on clioquinol, another kind of metal chelator, has demonstrated that oral administration of the drug, starting $6 \mathrm{~h}$ after induction of hemorrhage near the internal capsule by collagenase, alleviated motor dysfunction of rats (38).

\subsection{Glutamate}

Glutamate has long been recognized as the major excitatory neurotransmitter in the central nervous system (CNS). This amino acid is also well known as an important player in various CNS disorders, since over-activation of ionotropic glutamate receptors causes neuronal damage via processes called excitotoxicity. Several lines of evidence suggest that glutamate is involved in the pathogensis of ICH. Transient elevation of the extracellular concentration of glutamate in the perihematomal region was demonstrated in rabbits following injection of autologous blood into the gray matter of the cerebrum (39). Subsequently, the effect of memantine, a low-affinity blocker of the $N$-methyl-D-aspartate subtype of glutamate receptor-associated channels, was investigated in the collagenase-injection model in rats. Daily intraperitoneal administration of memantine, starting from 30 min after induction of $\mathrm{ICH}$, reduced hemorrhage volume, apoptotic cell death, neutrophil infiltration, and the number of microglia/macrophages in the periphery of hematoma. Neurological deficits associated with ICH were also ameliorated by this drug (40).

\subsection{Complement}

The complement cascade, consisting of interactions and associations of various serum and membrane-bound proteins, regulates inflammation, opsonization, and cytolysis and plays a key role in various disorders. This cascade may be involved in the pathogenesis of ICH (41), in part via participation in hemolysis (Fig. 1B). In the autologous blood-injection model in rats, perihematomal immunoreactivity against $\mathrm{C} 9$ was markedly elevated (42). Application of $\mathrm{N}$-acetylhepain, an inhibitor of complement activation, suppressed edema formation (42). Moreover, C3-deficient mice that underwent autologous blood injection exhibited less brain edema, lower HO-1 levels, less microglia activation, and neutrophil infiltration, concomitantly with alleviated deficits in motor functions, compared to wild-type mice (43). The deleterious role of $\mathrm{C} 3$ is also supported by a study using a C3a-receptor antagonist. Administration of a C3areceptor antagonist beginning $6 \mathrm{~h}$ after autologous blood injection in mice significantly reduced neurological dysfunction and tended to decrease brain edema (44). In contrast, the role of $\mathrm{C} 5$ in the pathogenesis of ICH is controversial. A study on genetically modified mice suggests that C5 deficiency exacerbates brain edema triggered by autologous blood injection (45), whereas a C5a-receptor antagonist, either alone or in combination with a C3a-receptor antagonist, has been shown to reduce neutrophil infiltration and to improve neurological and spatial memory functions after autologous blood injection in mice (46).

\subsection{Proinflammatory cytokines and other inflamma- tory mediators}

Pathogenic events in ICH are characterized by occurrence of various inflammatory events including microglial activation, neutrophil infiltration, increase in oxidative stress, and production of proinflammatory cytokines (47). Expression levels of tumor necrosis factor (TNF)- $\alpha$ are increased in response to injection of autologous blood or thrombin into the striatum (48) and in response to induction of ICH by collagenase (49). Suppression of TNF- $\alpha$ expression by administration of antisense oligonucleotide into the striatum reduced cell death within the hematoma and improved neurological deficits after collagenase-induced ICH in rats (49). In this context, we have recently proposed that TNF- $\alpha$ produced from activated microglia contributes to striatal tissue injury by thrombin in organotypic slice culture (31). Interleukin (IL)- $1 \beta$ may also be involved in the pathogenesis of ICH, since over-expression of IL-1-receptor antagonist significantly reduced brain edema induced by injection of autologous blood or thrombin into rat striatum (50).

Nuclear factor (NF)- $\kappa \mathrm{B}$ is a transcription factor that plays a key role in inflammatory reactions by regulating expression of various proinflammatory factors. Activation of NF- $\kappa \mathrm{B}$ is triggered promptly after experimental $\mathrm{ICH}$ by autologous blood injection and increased expression levels of NF- $\kappa$ B subunits are sustained for 7 days (51). Expression of inducible nitric oxide synthase (iNOS), a product of NF- $\kappa \mathrm{B}-$ regulated genes, is also upregulated following ICH (51). Contribution of iNOS to ICH pathogenesis is suggested by a finding that iNOSknockout mice exhibited reduced edema formation following collagenase-induced ICH, compared to wild-type mice (52).

\subsection{Protective factors}

In addition to the various harmful factors mentioned 
above, several intrinsic cytoprotective systems are also mobilized in response to $\mathrm{ICH}$, which may act to limit hemorrhage-associated tissue damage. For example, expression of heat shock protein 70 (HSP70), a molecular chaperone, is induced after ICH in neurons and glial cells (53). Prior induction of HSP70 by administration of geranylgeranylacetone in rats has been reported to afford neuroprotection and lessen neurological deficits associated with ICH induced by collagenase injection (54).

NF-E2-related factor 2 (Nrf2) may also act as an important component of the cytoprotective systems. Nrf2deficient mice exhibit worsened outcome after collagenase injection as compared to wild-type mice, characterized by increases in injury volume, neuron death, neutrophil infiltration, oxidative stress, and neurological deficit score (55). Because expression of Nrf2 can be upregulated by various small compounds with electrophilic properties, this protein may serve as a potential molecular target for drug therapy. Indeed, intraperitoneal injection of the Nrf2 activator sulforaphane at $30 \mathrm{~min}$ after autologous blood injection into the striatum upregulated expression of several Nrf2-regulated antioxidative and detoxifying enzymes such as glutathione $S$-transferase and $\mathrm{NAD}(\mathrm{P}) \mathrm{H}$ :quinone oxidoreductase 1 and lessened neurological deficit score, neutrophil infiltration, as well as oxidative stress (56). A follow-up study has demonstrated that Nrf2 activation leads to upregulation of haptoglobin expression in oligodendrocytes. Haptoglobin can bind and neutralize hemoglobin, thereby protecting neurons and oligodendrocytes from hemoglobin-related damage (57).

\section{Potential pharmacological interventions}

Several research groups have been engaged in exploration of future candidates for therapeutic drugs for ICH; and indeed, various promising results have been reported, at least in animal models. Most of the drugs showing efficacy in ICH models have already been shown to exert beneficial effects on other CNS disorders and to have antioxidative, anti-inflammatory, or neurotrophic/neuroprotective actions.

\subsection{Free radical scavengers}

An early study on a rat ICH model demonstrated that neurological deficits were significantly attenuated by intraperitoneal administration of dimethylthiourea (a scavenger of hydroxyl radical) or $\alpha$-phenyl- $N$-tert-butyl nitrone (a spin trapping agent) beginning $2 \mathrm{~h}$ after collagenase injection. However, these agents did not prevent ICH-associated neuron loss (58).

Edaravone is a radical scavenger used clinically for treatment of ischemic stroke in Japan. A study assessing the effect of edaravone showed that subcutaneous administration of this drug immediately after autologous blood injection in rats reduced edema and neurological deficits, together with reduction in oxidative DNA damage. Concerning reduction of edema, edaravone was effective even when administration was started $2 \mathrm{~h}$ after autologous blood injection (59).

Another free radical trapping agent, NXY-059, has been shown to exert beneficial effects in the collagenaseinduced ICH model in rats. Subcutaneous injection of NXY-059 starting from 30 min after collagenase injection diminished neurological impairment, neutrophil infiltration in the vicinity of hematoma, and occurrence of apoptotic cell death in the perihematomal region (60). Unfortunately, a clinical trial employing intravenous injection of NXY-059 starting within $6 \mathrm{~h}$ after ICH revealed no significant effect of the drug on clinical outcome (61).

\subsection{Growth factors and cytokines}

A prospective study on primary ICH patients has demonstrated that high serum levels of growth factors such as vascular endothelial growth factor, glanulocytecolony stimulating factor (G-CSF), and angiopoietin 1 are associated with good functional outcome and reduced lesion volume (62). With regard to G-CSF, daily intraperitoneal injection of this cytokine from $2 \mathrm{~h}$ after induction of ICH by collagenase in rats resulted in improved recovery from neurological deficits. G-CSF administration also produced beneficial effects on various pathological parameters, including reduction in edema and blood-brain barrier permeability and decreases in apoptosis, neutrophil infiltration, and the number of activated microglia/macrophages (63). A recent study suggested possible contribution of neurogenesis to the beneficial effect of G-CSF against ICH-induced neurological deficits. Indeed, G-CSF treatment increased the number of stem cells in the hemorrhagic region and promoted mobilization of circulating hematopoietic stem cells to the damaged brain areas (64).

Erythropoietin is also noteworthy as this pleiotropic cytokine exhibits neuroprotective activities in several $\mathrm{CNS}$ disease models. Concerning ICH, daily intraperitoneal administration of erythropoietin starting from $2 \mathrm{~h}$ after ICH induction by collagenase resulted in improved functional recovery and reduction in edema, hemorrhage volume, apoptotic cell death, and the appearance of neutrophils and activated microglia/macrophages. Erythropoietin also attenuated expression of TNF- $\alpha$ as well as a death receptor and its ligand Fas and Fas-L and prevented activation of caspases (65). Protective effects of erythropoietin and its long-acting analog darbepoetin have also been demonstrated in the autologous blood- 
injection model in rats (66).

\subsection{Minocycline}

Minocycline is originally known as a tetracycline type of antibiotic. However, many lines of evidence show that, independently of its antibiotic activities, this compound possesses neuroprotective properties. Neuroprotective activities of minocycline may be attributable to its anti-apoptotic, antioxidative, and anti-inflammatory actions.

The beneficial effect of minocycline on brains after ICH was first demonstrated by Power et al. (20). In vitro, minocycline attenuated expression of IL- $1 \beta$ and MMP12 in monocytoid cells; and in vivo, systemic treatment of rats with minocycline at 1 and $12 \mathrm{~h}$ after induction of ICH by collagenase injection reduced macrophage infiltration, microglia hypertrophy, and appearance of apoptotic cells, concomitantly with inhibition of MMP-12 expression. Moreover, minocycline treatment improved behavioral performance (20). Another study demonstrated that minocycline treatment starting immediately after autologous blood injection attenuated brain edema, brain tissue atrophy, and behavioral deficits in rats (67). Minocycline was ineffective in reducing brain infarct and behavioral deficits, despite suppressing activation of microglia/macrophages, when administration was started $3 \mathrm{~h}$ after ICH induction by collagenase (68). However, other investigators reported that minocycline administration beginning $6 \mathrm{~h}$ after collagenase-induced ICH in rats ameliorated brain tissue damage via reduction in edema, microvessel loss, neutrophil infiltration, and expression of TNF- $\alpha$ and MMP-12 (69), but had no beneficial effect on striatal tissue loss and neuron loss outside the hematoma (70). A recent publication proposed that delivery of a high concentration of minocycline locally into the brain, with supplementation via systemic administration, achieved better neuroprotection in the autologous bloodinjection model in mice (71).

\subsection{Statins}

Statins refer to a category of drugs used for treatment of hypercholesterolemia. Based on their inhibitory actions on hydroxymethylglutaryl-CoA reductase, these drugs interfere with cholesterol biosynthesis in the liver and lower serum cholesterol levels. Similar to the case with minocycline, potential applications of statins for the treatment of neurological disorders have been a topic of recent investigations.

In a rat autologous blood injection model, oral administration of atorvastatin starting from $24 \mathrm{~h}$ after $\mathrm{ICH}$ significantly reduced the severity of neurological deficits and the area of cell loss in the striatum (72). The authors attributed these effects of atorvastatin to the ability of this drug to increase synaptic plasticity, since expression of markers of synaptogenesis, immature neurons and neuronal migration was enhanced by the treatment (72). A later study by the same group (73) has demonstrated that simvastatin, in addition to atorvastatin, produced beneficial effects against ICH pathology. Simvastatin tended to produce greater effects in reducing hematoma volume and tissue loss than atorvastatin. Another group using a collagenase injection model also demonstrated that two-week administration of atorvastatin starting $6 \mathrm{~h}$ after induction of ICH reduced edema, brain atrophy, and occurrence of apoptosis. Expression of iNOS and the number of neutrophils and microglia/macrophages were also reduced by atorvastatin, and reduction in these pathological changes was accompanied by improved performance in sensorimotor activities in treated animals (74).

In contrast to these promising results in animal experiments, epidemiological studies draw controversial conclusions as to whether or not statin use brings beneficial influences on the clinical outcome of ICH. Retrospective studies on ICH patients in Johns Hopkins Hospital from 1999 to 2006 suggested association of prior statin use with decreased mortality (75) and decreased perihematomal edema (76). On the other hand, a prospective cohort study did not find association between prior use of statins and improvement in functional outcome or mortality after $\mathrm{ICH}(77)$.

\subsection{Nuclear receptor ligands}

Peroxisome proliferator-activated receptor- $\gamma(\operatorname{PPAR} \gamma)$ is a member of the nuclear receptor superfamily, regulating transcription of various genes including those related to lipid and glucose metabolism. With relation to CNS pathology, stimulation of PPAR $\gamma$ by ligands such as 15-deoxy- $\Delta^{12,14}$-prostaglandin $\mathrm{J}_{2}\left(15 \mathrm{~d}-\mathrm{PGJ}_{2}\right)$ has been reported to prevent microglial activation (78). Consistent with this fact, administration of $15 \mathrm{~d}-\mathrm{PGJ}_{2}$ directly into the hematoma reduced inflammatory responses associated with autologous blood injection, as shown by decreased NF- $\kappa$ B activation and neutrophil infiltration (79). These effects were accompanied by reduced apoptosis and improved behavioral functions in rats. In addition, stimulation of PPAR $\gamma$ by rosiglitazone, another agonist, enhanced the phagocytic activity of microglia in primary culture (80). Enhanced phagocytic activity of microglia toward red blood cells may promote hematoma resolution in vivo, thereby attenuating brain cell damage associated with ICH (Fig. 2A). Indeed, intraperitoneal administration of rosiglitazone starting from $24 \mathrm{~h}$ after autologous blood injection reduced hematoma volume and improved behavioral performance in mice (80).

There are several reports suggesting beneficial effects 

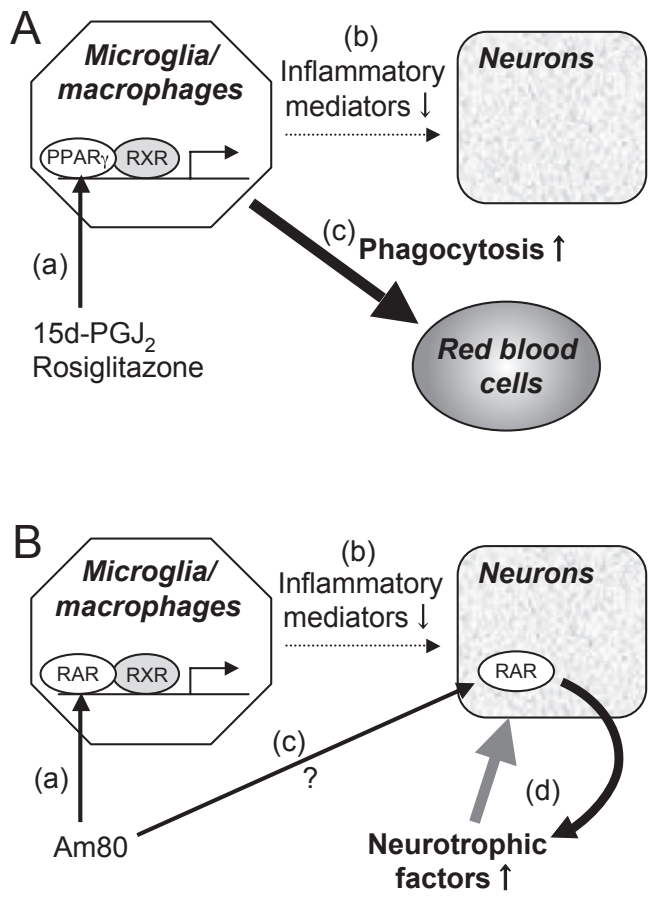

Fig. 2. Proposed mechanisms of action of nuclear receptor ligands in the brain after ICH. A) Peroxisome proliferator-activated receptor- $\gamma$ $(\operatorname{PPAR} \gamma)$ acts as a transcriptional regulator in combination with retinoid $\mathrm{X}$ receptor (RXR). Stimulation of PPAR $\gamma$ in microglia/macrophages by ligands such as $15 \mathrm{~d}-\mathrm{PGJ}_{2}$ and rosiglitazone (a) results in reduced production of inflammatory mediators (b) and enhanced phagocytic activity toward red blood cells in the hematoma (c). B) Similarly to PPAR $\gamma$, retinoic acid receptor (RAR) forms a heterodimer with RXR to regulate gene transcription, although RXR-independent mechanisms of RAR signaling may also exist. Stimulation of RAR in microglia/macrophages by the specific agonist Am80 (a) prevents activation of these cell populations and reduces inflammatory reactions (b). RAR agonist might also act on neurons (c) and enhance production of neurotrophic factors such as brain-derived neurotrophic factor that protects neurons in an autocrine/paracrine manner (d).

of the glucocorticoid dexamethasone in ICH animal models $(81,82)$, although an earlier clinical study casted caution on the usage of this drug for the treatment of primary supratentorial ICH (83). Intraperitoneal injection of dexamethasone in rats at 2 and $24 \mathrm{~h}$ after collagenase injection significantly reduced hematoma volume, neutrophil infiltration, and neurological deficits (82). Modulation of aquaporin-4 expression by dexamethasone might result in reduced edema formation after $\mathrm{ICH}$ (84).

We explored the possibility that retinoic acid receptors (RARs) may become a novel target of neuroprotective therapy for ICH. This assumption was based on the fact that RAR stimulation suppressed inflammatory responses of microglia (85). In addition, we recently found that RAR stimulation by the specific agonist Am80 (tamibarotene) increased expression of brain-derived neu- rotrophic factor in brain tissues and protected midbrain dopaminergic neurons from inflammatory degeneration $(86,87)$. Therefore, both the anti-inflammatory action and neurotrophic action of the RAR agonist might exert beneficial influences on the integrity of brain tissue after ICH (Fig. 2B). We examined the effect of Am80 on the collagenase-based ICH model in mice. Daily oral administration of Am80, starting from up to $6 \mathrm{~h}$ after induction of ICH, effectively prevented neuron loss within the hematoma. Am 80 treatment had no effect on injury volume or the extent of brain edema, but significantly reduced the number of activated microglia/macrophages and expansion of oxidative stress in the perihematomal region. Moreover, Am80 treatment improved recovery of mice from neurological deficits after ICH (88).

\subsection{Others}

Other miscellaneous targets and pharmacological interventions have been reported to produce therapeutic effects against ICH-associated pathology and neurological dysfunction. Tauroursodeoxycholic acid (TUDCA) is a derivative of the endogenous bile acid ursodeoxycholic acid, which has anti-apoptotic properties and alleviates endoplasmic reticulum stress. Administration of TUDCA through the internal carotid artery from up to $3 \mathrm{~h}$ after collagenase injection into the striatum reduced ICH-induced apoptotic events and improved motor performance in rats (89). Inhibition of apoptotic events and upregulation of neuroprotective gene products are also achieved by intraperitoneal injection of valproic acid, an anti-epileptic drug and histone deacetylase inhibitor. Indeed, valproic acid treatment reduced hematoma volume, inflammatory events, and neurological deficits, concomitantly with upregulation of HSP70 and antiapoptotic proteins Bcl-2 and Bcl-xl (90). Inhibitors of tissue-type transglutaminase (cystamine) and the ubiquitin-proteasome system (bortezomib) as well as an antagonist at AT1-angiotensin receptors (telmisartan) have also been reported to improve various pathological parameters associated with ICH $(91-93)$, although exactly how these molecular systems contribute to ICH pathogenesis remains to be determined.

Table 1 presents a list of drugs shown to be effective in ICH animal models. The list includes only drugs that showed significant beneficial effects, when systemic (not intracerebral) administration of the drug was performed in a post-treatment regimen, where the first dose was given at or more than $1 \mathrm{~h}$ after induction of $\mathrm{ICH}$.

\section{Perspectives}

Recent advances in basic research on ICH animal models have been elucidating key aspects of the patho- 
Table 1. List of drugs reported to show beneficial effects on ICH animal models in post-treatment regimen $* 1$

\begin{tabular}{|c|c|c|c|c|c|c|c|c|c|c|c|c|c|}
\hline \multirow[b]{2}{*}{ Drug name } & \multirow[b]{2}{*}{ Model $*^{2}$} & \multirow[b]{2}{*}{ Route } & \multirow[b]{2}{*}{$\begin{array}{l}\text { Timing of } \\
\text { administration }\end{array}$} & \multicolumn{9}{|c|}{ Parameters assessed $*^{3}$} & \multirow[b]{2}{*}{ Ref. } \\
\hline & & & & Behavior & Edema & $\begin{array}{l}\text { Volume of } \\
\text { injury or } \\
\text { hematoma }\end{array}$ & $\begin{array}{l}\text { Brain } \\
\text { atrophy }\end{array}$ & $\begin{array}{l}\text { Apoptosis } \\
\text { /Neurode- } \\
\text { generation }\end{array}$ & $\begin{array}{l}\text { Microglia } \\
\text { /Macro- } \\
\text { phages }\end{array}$ & $\begin{array}{l}\text { Neutro- } \\
\text { phils }\end{array}$ & $\begin{array}{l}\text { Cyto- } \\
\text { kines }\end{array}$ & $\begin{array}{l}\text { Oxidative } \\
\text { stress }\end{array}$ & \\
\hline Argatroban & $\mathrm{rat} / \mathrm{B}$ & i.p. & $\begin{array}{l}6 \mathrm{~h} \text { post, } \\
\text { continuous } \\
\text { infusion }\end{array}$ & & Yes & No & & & & & & & 8 \\
\hline BB-1101 & $\mathrm{rat} / \mathrm{C}$ & i.p. & $6 \mathrm{~h}$ post & & Yes & & & & & & & & 15 \\
\hline GM6001 & mouse/C & i.p. & $\begin{array}{l}2 \mathrm{~h} \text { post, } \\
\text { then every } 24 \mathrm{~h}\end{array}$ & Yes & Yes & Yes & & Yes & No & Yes & & Yes & 18 \\
\hline Deferoxamine & $\mathrm{rat} / \mathrm{B}$ & i.p. & $\begin{array}{l}2 \text { or } 6 \mathrm{~h} \text { post, } \\
\text { then every } 12 \mathrm{~h}\end{array}$ & Yes $* 4$ & Yes & & & & & & & Yes $*^{4}$ & 35 \\
\hline Deferoxamine & $\mathrm{rat} / \mathrm{B}$ & i.p. & $\begin{array}{l}2 \mathrm{~h} \text { post, } \\
\text { then every } 12 \mathrm{~h}\end{array}$ & Yes & & & Yes & & & & & & 100 \\
\hline Deferoxamine & $\mathrm{rat} / \mathrm{B}$ & i.m. & $\begin{array}{l}\text { up to } 48 \mathrm{~h} \text { post, } \\
\text { second injection } 4 \\
\mathrm{~h} \text { later, then every } \\
12 \mathrm{~h}\end{array}$ & Yes & Yes $* 5$ & & Yes $* 6$ & & & & & & 36 \\
\hline Clioquinol & $\mathrm{rat} / \mathrm{C}$ & p.o. & $\begin{array}{l}6 \mathrm{~h} \text { post, } \\
\text { then every } 24 \mathrm{~h}\end{array}$ & Yes & & & & Yes & & & & & 38 \\
\hline C3aRA & mouse/B & i.p. & $\begin{array}{l}6 \text { and } 12 \mathrm{~h} \text { post, } \\
\text { then twice daily }\end{array}$ & Yes & & No & & & No & Yes & & & 44 \\
\hline C5aRA & mouse/B & i.p. & $\begin{array}{l}6 \text { and } 12 \mathrm{~h} \text { post, } \\
\text { then twice daily }\end{array}$ & Yes & No & & & & No & Yes & & & 46 \\
\hline C3aRA/C5aRA & mouse/B & i.p. & $\begin{array}{l}6 \text { and } 12 \mathrm{~h} \text { post, } \\
\text { then twice daily }\end{array}$ & Yes & Yes & & & & No & Yes & & & 46 \\
\hline Dimethylthiourea & $\mathrm{rat} / \mathrm{C}$ & i.p. & $\begin{array}{l}2 \mathrm{~h} \text { post, } \\
\text { then twice daily }\end{array}$ & Yes & & No & No & No & & & & & 58 \\
\hline PBN & $\mathrm{rat} / \mathrm{C}$ & i.p. & $\begin{array}{l}2 \mathrm{~h} \text { post, } \\
\text { then twice daily }\end{array}$ & Yes & & No & No & No & & & & & 58 \\
\hline G-CSF & $\mathrm{rat} / \mathrm{C}$ & i.p. & $2 \mathrm{~h}$ post, then daily & Yes & Yes & No & Yes & Yes & Yes & Yes & & & 63 \\
\hline G-CSF & $\mathrm{rat} / \mathrm{C}$ & i.p. & $\begin{array}{l}24 \mathrm{~h} \text { post, } \\
\text { then daily }\end{array}$ & Yes & & & & & & & & & 64 \\
\hline Erythropoietin & $\mathrm{rat} / \mathrm{C}$ & i.p. & $2 \mathrm{~h}$ post, then daily & Yes & Yes & Yes & Yes & Yes & Yes & Yes & Yes & & 65 \\
\hline Minocycline & $\mathrm{rat} / \mathrm{C}$ & i.p. & $\begin{array}{l}1 \text { and } 12 \mathrm{~h} \text { post, } \\
\text { then twice daily } \\
\text { for } 1 \text { week, } \\
\text { and once daily } \\
\text { for another week }\end{array}$ & Yes & & & & Yes & Yes & No & Yes & & 20 \\
\hline Minocycline & $\mathrm{rat} / \mathrm{C}$ & i.p. & $\begin{array}{l}3 \mathrm{~h} \text { post, } \\
\text { then twice daily }\end{array}$ & No & & No & & & Yes & & & & 68 \\
\hline Minocycline & $\mathrm{rat} / \mathrm{C}$ & i.p. & $6 \mathrm{~h}, 1 \mathrm{~d}$ and $2 \mathrm{~d}$ post & & Yes & & & & & Yes & Yes & & 69 \\
\hline Minocycline & $\mathrm{rat} / \mathrm{C}$ & $\begin{array}{l}\text { i.v. } \\
\text { /i.p. }\end{array}$ & $\begin{array}{l}6,24,48, \\
\text { and } 72 \mathrm{~h} \text { post }\end{array}$ & & & No & & No & Yes & Yes & & & 70 \\
\hline Atorvastatin & $\mathrm{rat} / \mathrm{C}$ & p.o. & $6 \mathrm{~h}$ post, then daily & Yes & Yes & No & Yes & Yes & Yes & Yes & & & 74 \\
\hline Atorvastatin & $\mathrm{rat} / \mathrm{B}$ & p.o. & $\begin{array}{l}24 \mathrm{~h} \text { post, } \\
\text { then daily }\end{array}$ & Yes & & No & Yes & Yes & & & & & $\begin{array}{l}72, \\
73\end{array}$ \\
\hline Simvastatin & $\mathrm{rat} / \mathrm{B}$ & p.o. & $\begin{array}{l}24 \mathrm{~h} \text { post, } \\
\text { then daily }\end{array}$ & Yes & & Yes & Yes & & & & & & 73 \\
\hline Rosiglitazone & mouse/B & i.p. & $\begin{array}{l}24 \mathrm{~h} \text { post, } \\
\text { then daily }\end{array}$ & Yes & & Yes & & & & & Yes & Yes & 80 \\
\hline Dexamethasone & $\mathrm{rat} / \mathrm{C}$ & i.p. & 1 and $24 \mathrm{~h}$ post & Yes & & Yes & & Yes & & Yes & & & 81 \\
\hline Dexamethasone & $\mathrm{rat} / \mathrm{C}$ & i.p. & $\begin{array}{l}2,4, \text { or } 6 \mathrm{~h} \text { post, } \\
\text { then } 24 \mathrm{~h} \text { post }\end{array}$ & Yes $* 4$ & & Yes & & Yes *4 & & Yes & & & 82 \\
\hline Am80 & mouse/C & p.o. & $\begin{array}{l}2 \text { or } 6 \mathrm{~h} \text { post, } \\
\text { then every } 24 \mathrm{~h}\end{array}$ & Yes & No & No & & Yes & Yes & & & Yes & 88 \\
\hline TUDCA & $\mathrm{rat} / \mathrm{C}$ & i.a. & 1 or $3 \mathrm{~h}$ post & Yes & & Yes & & Yes & & & & & 89 \\
\hline Valproic acid & $\mathrm{rat} / \mathrm{C}$ & i.p. & $\begin{array}{l}2 \mathrm{~h} \text { post, } \\
\text { then twice daily }\end{array}$ & Yes & No & Yes & Yes & Yes & Yes & Yes & Yes & & 90 \\
\hline Cystamine & $\mathrm{rat} / \mathrm{B}$ & i.p. & $2 \mathrm{~h}$ post, then daily & Yes & Yes & & & Yes & & & & & 91 \\
\hline Bortezomib & $\mathrm{rat} / \mathrm{C}$ & i.v. & $2 \mathrm{~h}$ post & & Yes & Yes & & Yes & Yes & Yes & Yes & & 92 \\
\hline Telmisartan & $\mathrm{rat} / \mathrm{C}, \mathrm{B}$ & p.o. & $2 \mathrm{~h}$ post & Yes & Yes & Yes & & Yes & Yes & Yes & Yes & Yes & 93 \\
\hline
\end{tabular}

${ }^{* 1}$ See text and figures for details of the actions of each drug. Actions of argatroban, BB-1101, GM6001, deferoxamine, clioquinol, C3aRA, and C5aRA are illustrated in Fig. 1 and mentioned in section 2. Actions of other drugs are mentioned in section 3. The mechanisms of actions of rosiglitazone and Am80 are also illustrated in Fig. 2 . ${ }^{2}$ ' $\mathrm{C}$ ' represents the collagenase-injection model, and 'B' represents the autologous blood-injection model. *3' 'Yes' means that the pathological change was alleviated by drug treatment, and 'No' means that the drug showed no beneficial effect on the respective parameter. ${ }^{* 4}$ Effective when administered up to $2 \mathrm{~h}$ postinduction of ICH, ${ }^{* 5}$ up to $12 \mathrm{~h}$ post, ${ }^{* 6}$ up to $24 \mathrm{~h}$ post. Abbreviations: C3aRA, complement C3a-receptor antagonist; C5aRA, complement C5a-receptor antagonist; PBN, $\alpha$-phenyl- $N$-tert-butyl nitrone; G-CSF, glanulocyte colony-stimulating factor; TUDCA, tauroursodeoxycholic acid. 
genesis of $\mathrm{ICH}$, several of which may have potentials to be targeted by drug therapies. However, detailed mechanisms of ICH pathogenesis still remain largely unexplored. Microarray analyses have indicated that hundreds of genes, including those involved in inflammation, metabolism, and neuronal signal transduction, are upregulated or downregulated in the rat $\mathrm{ICH}$ model and human ICH patients $(94,95)$. Clarification of the roles of these gene products in $\mathrm{ICH}$ pathogenesis might reveal novel therapeutic targets.

On the experimental basis, the number of drugs effective for improving pathological and neurological outcomes of ICH is increasing. However, whether these drugs also show efficacy in human patients remain unproven. A problem is that many studies on drug effects in animal models focused mainly on the acute phase of neuropathology, and data of the long-term outcome of drug treatments over months are still scarce. During the extended time course after $\mathrm{ICH}$, repair processes may take place in the damaged brain, which may also be affected by drug treatments. For example, inhibition of the protein kinase Src can improve the acute outcome, such as neurodegeneration and abnormal behavior, after autologous blood injection in rats (96). On the other hand, prolonged inhibition of Src in the ICH model disturbs repair processes in the neurovascular niche that forms the blood-brain barrier (97), which might worsen long-term outcome. Notably, several drugs including G-CSF (64) and statins (73) have been reported to stimulate neurogenesis in hemorrhagic brain, but contribution of neurogenesis to the effects of these drugs in improving pathological and neurological parameters is unclear at present.

Another issue to be considered is that the severity of neurological symptoms after ICH may be closely associated with the extent of white matter injury $(38,98)$, whereas the majority of experimental studies is concerned about loss of neuronal cell bodies. We should keep in mind that from the clinical point of view, the most important issues in $\mathrm{ICH}$ therapies are reduction of mortality and alleviation of neurological deficits. In this context, research on ICH animal models may require some kinds of refinement for the experimental results to be extrapolated into clinical situations. Without these considerations, we might be trapped into pitfalls reminiscent of those experienced in research on ischemic stroke, where a wide variety of treatments were proven to be effective in animal models but the vast majority of them failed in clinical trials (99).

\section{Acknowledgments}

This work was supported by grants from Itsuu Laboratory, The Smoking Research Foundation, Takeda Science Foundation, and Mitsubishi Pharma Research Foundation and by a Grant-in-Aid for Scientific Research (20390026) from The Japan Society for the Promotion of Science.

\section{References}

1 Xi G, Keep RF, Hoff JT. Mechanisms of brain injury after intracerebral haemorrhage. Lancet Neurol. 2006;5:53-63.

2 Suzuki Y. Role of tissue-type plasminogen activator in ischemic stroke. J Pharmacol Sci. 2010;113:203-207.

3 Qureshi AI, Mendelow AD, Hanley DF. Intracerebral haemorrhage. Lancet. 2009;373:1632-1644.

4 James ML, Warner DS, Laskowitz DT. Preclinical models of intracerebral hemorrhage: a translational perspective. Neurocrit Care. 2008;9:139-152.

5 Xi G, Reiser G, Keep RF. The role of thrombin and thrombin receptors in ischemic, hemorrhagic and traumatic brain injury: deleterious or protective? J Neurochem. 2003;84:3-9.

6 Kai Y, Maeda Y, Sasaki T, Kanaide H, Hirano K. Basic and translational research on proteinase-activated receptors: the role of thrombin receptor in cerebral vasospasm in subarachnoid hemorrhage. J Pharmacol Sci. 2008;108:426-432.

7 Lee KR, Colon GP, Betz AL, Keep RF, Kim S, Hoff JT. Edema from intracerebral hemorrhage: the role of thrombin. J Neurosurg. 1996;84:91-96.

8 Kitaoka T, Hua Y, Xi G, Hoff JT, Keep RF. Delayed argatroban treatment reduces edema in a rat model of intracerebral hemorrhage. Stroke. 2002;33:3012-3018.

9 Lee KR, Kawai N, Kim S, Sagher O, Hoff JT. Mechanisms of edema formation after intracerebral hemorrhage: effects of thrombin on cerebral blood flow, blood-brain barrier permeability, and cell survival in a rat model. J Neurosurg. 1997;86:272-278.

10 Fujimoto S, Katsuki H, Kume T, Akaike A. Thrombin-induced delayed injury involves multiple and distinct signaling pathways in the cerebral cortex and the striatum in organotypic slice cultures. Neurobiol Dis. 2006;22:130-142.

11 Fujimoto S, Katsuki H, Ohnishi M, Takagi M, Kume T, Akaike A. Thrombin induces striatal neurotoxicity depending on mitogen-activated protein kinase pathways in vivo. Neuroscience. 2007;144:694-701.

12 Fujimoto S, Katsuki H, Ohnishi M, Takagi M, Kume T, Akaike A. Plasminogen potentiates thrombin cytotoxicity and contributes to pathology of intracerebral hemorrhage in rats. J Cereb Blood Flow Metab. 2008;28:506-515.

13 Xue M, Hollenberg MD, Yong VW. Combination of thrombin and matrix metalloproteinase- 9 exacerbates neurotoxicity in cell culture and intracerebral hemorrhage in mice. J Neurosci. 2006; 26:10281-10291.

14 Rosenberg GA. Matrix metalloproteinases and their multiple roles in neurodegenerative diseases. Lancet Neurol. 2009;8:205216.

15 Rosenberg GA, Navratil M. Metalloproteinase inhibition blocks edema in intracerebral hemorrhage in the rat. Neurology. 1997; 48:921-926.

16 Alvarez-Sabín J, Delgado P, Abilleira S, Molina CA, Arenillas J, Ribó M, et al. Temporal profile of matrix metalloproteinases and 
their inhibitors after spontaneous intracerebral hemorrhage: relationship to clinical and radiological outcome. Stroke. 2004;35: 1316-1322.

17 Tejima E, Zhao BQ, Tsuji K, Rosell A, van Leyen K, Gonzalez $\mathrm{RG}$, et al. Astrocytic induction of matrix metalloproteinase- 9 and edema in brain hemorrhage. J Cereb Blood Flow Metab. 2007; 27:460-468.

18 Wang J, Tsirka SE. Neuroprotection by inhibition of matrix metalloproteinases in a mouse model of intracerebral haemorrhage. Brain. 2005;128:1622-1633.

19 Xue M, Fan Y, Liu S, Zygun DA, Demchuk A, Yong VW. Contributions of multiple proteases to neurotoxicity in a mouse model of intracerebral haemorrhage. Brain. 2009;132:26-36.

20 Power C, Henry S, Del Bigio MR, Larsen PH, Corbett D, Imai Y, et al. Intracerebral hemorrhage induces macrophage activation and matrix metalloproteinases. Ann Neurol. 2003;53:731-742.

21 Wells JE, Biernaskie J, Szymanska A, Larsen PH, Yong VW, Corbett D. Matrix metalloproteinase (MMP)-12 expression has a negative impact on sensorimotor function following intracerebral haemorrhage in mice. Eur J Neurosci. 2005;21:187-196.

22 Tang J, Liu J, Zhou C, Alexander JS, Nanda A, Granger DN, et al. Mmp-9 deficiency enhances collagenase-induced intracerebral hemorrhage and brain injury in mutant mice. J Cereb Blood Flow Metab. 2004;24:1133-1145.

23 Grossetete M, Rosenberg GA. Matrix metalloproteinase inhibition facilitates cell death in intracerebral hemorrhage in mouse. $\mathrm{J}$ Cereb Blood Flow Metab. 2008;28:752-763.

24 Wagner KR, Sharp FR, Ardizzone TD, Lu A, Clark JF. Heme and iron metabolism: role in cerebral hemorrhage. J Cereb Blood Flow Metab. 2003;23:629-652.

25 Lara FA, Kahn SA, da Fonseca AC, Bahia CP, Pinho JP, GracaSouza AV, et al. On the fate of extracellular hemoglobin and heme in brain. J Cereb Blood Flow Metab. 2009;29:1109-1120.

26 Huang FP, Xi G, Keep RF, Hua Y, Nemoianu A, Hoff JT. Brain edema after experimental intracerebral hemorrhage: role of hemoglobin degradation products. J Neurosurg. 2002;96:287-293.

27 Koeppen AH, Dickson AC, Smith J. Heme oxygenase in experimental intracerebral hemorrhage: the benefit of tin-mesoporphyrin. J Neuropathol Exp Neurol. 2004;63:587-597.

28 Wang J, Doré S. Heme oxygenase-1 exacerbates early brain injury after intracerebral haemorrhage. Brain. 2007;130:16431652 .

29 Wagner KR, Hua Y, de Courten-Myers GM, Broderick JP, Nishimura RN, Lu SY, et al. Tin-mesoporphyrin, a potent heme oxygenase inhibitor, for treatment of intracerebral hemorrhage: in vivo and in vitro studies. Cell Mol Biol. 2000;46:597-608.

30 Ohnishi M, Katsuki H, Fujimoto S, Takagi M, Kume T, Akaike A. Involvement of thrombin and mitogen-activated protein kinase pathways in hemorrhagic brain injury. Exp Neurol. 2007;206: 43-52.

31 Ohnishi M, Katsuki H, Izumi Y, Kume T, Takada-Takatori Y, Akaike A. Mitogen-activated protein kinases support survival of activated microglia that mediate thrombin-induced striatal injury in organotypic slice culture. J Neurosci Res. 2010;88:21552164.

32 Ohnishi M, Katsuki H, Unemura K, Izumi Y, Kume T, TakadaTakatori Y, et al. Heme oxygenase-1 contributes to pathology associated with thrombin-induced striatal and cortical injury in organotypic slice culture. Brain Res. 2010;1347:170-178.

33 Wu J, Hua Y, Keep RF, Nakamura T, Hoff JT, Xi G. Iron and iron-handling proteins in the brain after intracerebral hemorrhage. Stroke. 2003;34:2964-2969.

34 Pérez de la Ossa N, Sobrino T, Silva Y, Blanco M, Millán M, Gomis M, et al. Iron-related brain damage in patients with intracerebral hemorrhage. Stroke. 2010;41:810-813.

35 Nakamura T, Keep RF, Hua Y, Schallert T, Hoff JT, Xi G. Deferoxamine-induced attenuation of brain edema and neurological deficits in a rat model of intracerebral hemorrhage. J Neurosurg. 2004;100:672-678.

36 Okauchi M, Hua Y, Keep RF, Morgenstern LB, Schallert T, Xi G. Deferoxamine treatment for intracerebral hemorrhage in aged rats: therapeutic time window and optimal duration. Stroke. 2010;41:375-382.

37 Warkentin LM, Auriat AM, Wowk S, Colbourne F. Failure of deferoxamine, an iron chelator, to improve outcome after collagenase-induced intracerebral hemorrhage in rats. Brain Res. 2010;1309:95-103.

38 Masuda T, Hida H, Kanda Y, Aihara N, Ohta K, Yamada K, et al. Oral administration of metal chelator ameliorates motor dysfunction after a small hemorrhage near the internal capsule in rat. $\mathrm{J}$ Neurosci Res. 2007;85:213-222.

39 Qureshi AI, Ali Z, Suri MF, Shuaib A, Baker G, Todd K, et al. Extracellular glutamate and other amino acids in experimental intracerebral hemorrhage: an in vivo microdialysis study. Crit Care Med. 2003;31:1482-1489.

40 Lee ST, Chu K, Jung KH, Kim J, Kim EH, Kim SJ, et al. Memantine reduces hematoma expansion in experimental intracerebral hemorrhage, resulting in functional improvement. J Cereb Blood Flow Metab. 2006;26:536-544.

41 Ducruet AF, Zacharia BE, Hickman ZL, Grobelny BT, Yeh ML, Sosunov SA, et al. The complement cascade as a therapeutic target in intracerebral hemorrhage. Exp Neurol. 2009;219:398 403.

42 Hua Y, Xi G, Keep RF, Hoff JT. Complement activation in the brain after experimental intracerebral hemorrhage. J Neurosurg. 2000;92:1016-1022.

43 Yang S, Nakamura T, Hua Y, Keep RF, Younger JG, He Y, et al. The role of complement $\mathrm{C} 3$ in intracerebral hemorrhage-induced brain injury. J Cereb Blood Flow Metab. 2006;26:1490-1495.

44 Rynkowski MA, Kim GH, Garrett MC, Zacharia BE, Otten ML, Sosunov SA, et al. C3a receptor antagonist attenuates brain injury after intracerebral hemorrhage. J Cereb Blood Flow Metab. 2009; 29:98-107.

45 Nakamura T, Xi G, Hua Y, Schallert T, Hoff JT, Keep RF. Intracerebral hemorrhage in mice: model characterization and application for genetically modified mice. J Cereb Blood Flow Metab. 2004;24:487-494.

46 Garrett MC, Otten ML, Starke RM, Komotar RJ, Magotti P, Lambris JD, et al. Synergistic neuroprotective effects of C3a and C5a receptor blockade following intracerebral hemorrhage. Brain Res. 2009;1298:171-177.

47 Wang J, Doré S. Inflammation after intracerebral hemorrhage. J Cereb Blood Flow Metab. 2007;27:894-908.

48 Hua Y, Wu J, Keep RF, Nakamura T, Hoff JT, Xi G. Tumor necrosis factor- $\alpha$ increases in the brain after intracerebral hemorrhage and thrombin stimulation. Neurosurgery. 2006;58:542550.

49 Mayne M, Ni W, Yan HJ, Xue M, Johnston JB, Del Bigio MR, et al. Antisense oligodeoxynucleotide inhibition of tumor necrosis factor- $\alpha$ expression is neuroprotective after intracerebral 
hemorrhage. Stroke. 2001;32:240-248.

50 Masada T, Hua Y, Xi G, Yang GY, Hoff JT, Keep RF. Attenuation of intracerebral hemorrhage and thrombin-induced brain edema by overexpression of interleukin-1 receptor antagonist. J Neurosurg. 2001;95:680-686.

51 Zhao X, Zhang Y, Strong R, Zhang J, Grotta JC, Aronowski J. Distinct patterns of intracerebral hemorrhage-induced alterations in NF- $\kappa \mathrm{B}$ subunit, iNOS, and COX-2 expression. J Neurochem. 2007;101:652-663.

52 Kim DW, Im SH, Kim JY, Kim DE, Oh GT, Jeong SW. Decreased brain edema after collagenase-induced intracerebral hemorrhage in mice lacking the inducible nitric oxide synthase gene. J Neurosurg. 2009;111:995-1000.

53 Matz PG, Weinstein PR, Sharp FR. Heme oxygenase-1 and heat shock protein 70 induction in glia and neurons throughout rat brain after experimental intracerebral hemorrhage. Neurosurgery. 1997;40:152-160.

54 Sinn DI, Chu K, Lee ST, Song EC, Jung KH, Kim EH, et al. Pharmacological induction of heat shock protein exerts neuroprotective effects in experimental intracerebral hemorrhage. Brain Res. 2007;1135:167-176.

55 Wang J, Fields J, Zhao C, Langer J, Thimmulappa RK, Kensler $\mathrm{TW}$, et al. Role of Nrf2 in protection against intracerebral hemorrhage injury in mice. Free Radic Biol Med. 2007;43:408-414.

56 Zhao X, Sun G, Zhang J, Strong R, Dash PK, Kan YW, et al. Transcription factor Nrf2 protects the brain from damage produced by intracerebral hemorrhage. Stroke. 2007;38:3280-3286.

57 Zhao X, Song S, Sun G, Strong R, Zhang J, Grotta JC, et al. Neuroprotective role of haptoglobin after intracerebral hemorrhage. J Neurosci. 2009;29:15819-15827.

58 Peeling J, Yan HJ, Chen SG, Campbell M, Del Bigio MR. Protective effects of free radical inhibitors in intracerebral hemorrhage in rat. Brain Res. 1998;795:63-70.

59 Nakamura T, Kuroda Y, Yamashita S, Zhang X, Miyamoto O, Tamiya $\mathrm{T}$, et al. Edaravone attenuates brain edema and neurologic deficits in a rat model of acute intracerebral hemorrhage. Stroke. 2008;39:463-469.

60 Peeling J, Del Bigio MR, Corbett D, Green AR, Jackson DM. Efficacy of disodium 4-[(tert-butylimino)methyl]benzene-1,3disulfonate $N$-oxide (NXY-059), a free radical trapping agent, in a rat model of hemorrhagic stroke. Neuropharmacology. 2001; 40:433-439.

61 Lyden PD, Shuaib A, Lees KR, Davalos A, Davis SM, Diener $\mathrm{HC}$, et al. Safety and tolerability of NXY-059 for acute intracerebral hemorrhage: the CHANT Trial. Stroke. 2007;38:22622269.

62 Sobrino T, Arias S, Rodríguez-González R, Brea D, Silva Y, de la Ossa NP, et al. High serum levels of growth factors are associated with good outcome in intracerebral hemorrhage. J Cereb Blood Flow Metab. 2009;29:1968-1974.

63 Park HK, Chu K, Lee ST, Jung KH, Kim EH, Lee KB, et al. Granulocyte colony-stimulating factor induces sensorimotor recovery in intracerebral hemorrhage. Brain Res. 2005;1041:125131.

64 Zhang L, Shu XJ, Zhou HY, Liu W, Chen Y, Wang CL, et al. Protective effect of granulocyte colony-stimulating factor on intracerebral hemorrhage in rat. Neurochem Res. 2009;34: 1317-1323.

65 Lee ST, Chu K, Sinn DI, Jung KH, Kim EH, Kim SJ, et al. Erythropoietin reduces perihematomal inflammation and cell death with eNOS and STAT3 activations in experimental intracerebral hemorrhage. J Neurochem. 2006;96:1728-1739.

66 Grasso G, Graziano F, Sfacteria A, Carletti F, Meli F, Maugeri R, et al. Neuroprotective effect of erythropoietin and darbepoetin alfa after experimental intracerebral hemorrhage. Neurosurgery. 2009;65:763-769.

67 Wu J, Yang S, Xi G, Fu G, Keep RF, Hua Y. Minocycline reduces intracerebral hemorrhage-induced brain injury. Neurol Res. 2009;31:183-188.

68 Szymanska A, Biernaskie J, Laidley D, Granter-Button S, Corbett D. Minocycline and intracerebral hemorrhage: influence of injury severity and delay to treatment. Exp Neurol. 2006;197:189-196.

69 Wasserman JK, Schlichter LC. Minocycline protects the bloodbrain barrier and reduces edema following intracerebral hemorrhage in the rat. Exp Neurol. 2007;207:227-237.

70 Wasserman JK, Schlichter LC. Neuron death and inflammation in a rat model of intracerebral hemorrhage: effects of delayed minocycline treatment. Brain Res. 2007;1136:208-218.

71 Xue M, Mikliaeva EI, Casha S, Zygun D, Demchuk A, Yong VW. Improving outcomes of neuroprotection by minocycline: guides from cell culture and intracerebral hemorrhage in mice. Am J Pathol. 2010;176:1193-1202.

72 Seyfried D, Han Y, Lu D, Chen J, Bydon A, Chopp M. Improvement in neurological outcome after administration of atorvastatin following experimental intracerebral hemorrhage in rats. J Neurosurg. 2004;101:104-107.

73 Karki K, Knight RA, Han Y, Yang D, Zhang J, Ledbetter KA, et al. Simvastatin and atorvastatin improve neurological outcome after experimental intracerebral hemorrhage. Stroke. 2009;40: 3384-3389.

74 Jung KH, Chu K, Jeong SW, Han SY, Lee ST, Kim JY, et al. HMG-CoA reductase inhibitor, atorvastatin, promotes sensorimotor recovery, suppressing acute inflammatory reaction after experimental intracerebral hemorrhage. Stroke. 2004;35:17441749.

75 Naval NS, Abdelhak TA, Zeballos P, Urrunaga N, Mirski MA, Carhuapoma JR. Prior statin use reduces mortality in intracerebral hemorrhage. Neurocrit Care. 2008;8:6-12.

76 Naval NS, Abdelhak TA, Urrunaga N, Zeballos P, Mirski MA, Carhuapoma JR. An association of prior statin use with decreased perihematomal edema. Neurocrit Care. 2008;8:13-18.

77 FitzMaurice E, Wendell L, Snider R, Schwab K, Chanderraj R, Kinnecom C, et al. Effect of statins on intracerebral hemorrhage outcome and recurrence. Stroke. 2008;39:2151-2154.

78 Drew PD, Xu J, Storer PD, Chavis JA, Racke MK. Peroxisome proliferator-activated receptor agonist regulation of glial activation: relevance to CNS inflammatory disorders. Neurochem Int. 2006;49:183-189.

79 Zhao X, Zhang Y, Strong R, Grotta JC, Aronowski J. 15d-Prostaglandin $\mathrm{J}_{2}$ activates peroxisome proliferator-activated receptor- $\gamma$, promotes expression of catalase, and reduces inflammation, behavioral dysfunction, and neuronal loss after intracerebral hemorrhage in rats. J Cereb Blood Flow Metab. 2006;26:811-820.

80 Zhao X, Sun G, Zhang J, Strong R, Song W, Gonzales N, et al. Hematoma resolution as a target for intracerebral hemorrhage treatment: role for peroxisome proliferator-activated receptor $\gamma$ in microglia/macrophages. Ann Neurol. 2007;61:352-362.

81 Lema PP, Girard C, Vachon P. Evaluation of dexamethasone for the treatment of intracerebral hemorrhage using a collagenaseinduced intracerebral hematoma model in rats. J Vet Pharmacol 
Ther. 2004;27:321-328.

82 Savard C, Lema PP, Hélie P, Vachon P. Effects of timing of dexamethasone treatment on the outcome of collagenase-induced intracerebral hematoma in rats. Comp Med. 2009;59:444-448.

83 Poungvarin N, Bhoopat W, Viriyavejakul A, Rodprasert P, Buranasiri P, Sukondhabhant S, et al. Effects of dexamethasone in primary supratentorial intracerebral hemorrhage. N Engl J Med. 1987;316:1229-1233.

84 Gu YT, Zhang H, Xue YX. Dexamethasone treatment modulates aquaporin-4 expression after intracerebral hemorrhage in rats. Neurosci Lett. 2007;413:126-131.

85 van Neerven S, Kampmann E, Mey J. RAR/RXR and PPAR/ RXR signaling in neurological and psychiatric diseases. Prog Neurobiol. 2008;85:433-451.

86 Katsuki H, Kurimoto E, Takemori S, Kurauchi Y, Hisatsune A, Isohama Y, et al. Retinoic acid receptor stimulation protects midbrain dopaminergic neurons from inflammatory degeneration via BDNF-mediated signaling. J Neurochem. 2009;110:707718.

87 Kurauchi Y, Hisatsune A, Isohama Y, Sawa T, Akaike T, Shudo $\mathrm{K}$, et al. Midbrain dopaminergic neurons utilize nitric oxide/ cyclic GMP signaling to recruit ERK that links retinoic acid receptor stimulation to up-regulation of BDNF. J Neurochem. in press. (doi: 10.1111/j.1471-4159.2010.06916.x)

88 Matsushita H, Hijioka M, Hisatsune A, Isohama Y, Shudo K, Katsuki H. A retinoic acid receptor agonist Am80 rescues neurons, attenuates inflammatory reactions, and improves behavioral recovery after intracerebral hemorrhage in mice. J Cereb Blood Flow Metab. in press. (doi: 10.1038/jcbfm.2010.80)

89 Rodrigues CM, Sola S, Nan Z, Castro RE, Ribeiro PS, Low WC, et al. Tauroursodeoxycholic acid reduces apoptosis and protects against neurological injury after acute hemorrhagic stroke in rats. Proc Natl Acad Sci U S A. 2003;100:6087-6092.

90 Sinn DI, Kim SJ, Chu K, Jung KH, Lee ST, Song EC, et al. Valproic acid-mediated neuroprotection in intracerebral hemorrhage via histone deacetylase inhibition and transcriptional activation. Neurobiol Dis. 2007;26:464-472.

91 Okauchi M, Xi G, Keep RF, Hua Y. Tissue-type transglutaminase and the effects of cystamine on intracerebral hemorrhage-induced brain edema and neurological deficits. Brain Res. 2009;1249: 229-236.

92 Sinn DI, Lee ST, Chu K, Jung KH, Kim EH, Kim JM, et al. Proteasomal inhibition in intracerebral hemorrhage: neuroprotective and anti-inflammatory effects of bortezomib. Neurosci Res. 2007;58:12-18.

93 Jung KH, Chu K, Lee ST, Kim SJ, Song EC, Kim EH, et al. Blockade of AT1 receptor reduces apoptosis, inflammation, and oxidative stress in normotensive rats with intracerebral hemorrhage. J Pharmacol Exp Ther. 2007;322:1051-1058.

94 Lu A, Tang Y, Ran R, Ardizzone TL, Wagner KR, Sharp FR. Brain genomics of intracerebral hemorrhage. J Cereb Blood Flow Metab. 2006;26:230-252.

95 Carmichael ST, Vespa PM, Saver JL, Coppola G, Geschwind $\mathrm{DH}$, Starkman S, et al. Genomic profiles of damage and protection in human intracerebral hemorrhage. J Cereb Blood Flow Metab. 2008;28:1860-1875.

96 Ardizzone TD, Zhan X, Ander BP, Sharp FR. SRC kinase inhibition improves acute outcomes after experimental intracerebral hemorrhage. Stroke. 2007;38:1621-1625.

97 Liu DZ, Ander BP, Xu H, Shen Y, Kaur P, Deng W, et al. Bloodbrain barrier breakdown and repair by Src after thrombin-induced injury. Ann Neurol. 2010;67:526-533.

98 Medana IM, Esiri MM. Axonal damage: a key predictor of outcome in human CNS diseases. Brain. 2003;126:515-530.

99 Ginsberg MD. Neuroprotection for ischemic stroke: past, present and future. Neuropharmacology. 2008;55:363-389.

100 Hua Y, Nakamura T, Keep RF, Wu J, Schallert T, Hoff JT, et al. Long-term effects of experimental intracerebral hemorrhage: the role of iron. J Neurosurg. 2006;104:305-312. 